\title{
Bangladesh Health Service Delivery: Innovative NGO and Private Sector Partnerships
}

\author{
Md Rubaiyath Sarwar
}

\begin{abstract}
The recent health service delivery achievements in Bangladesh have been attributed, in part, to partnerships between the government and non-state actors and the early and rapid adoption of innovations. Through the analysis of two case studies, this article examines the factors contributing to successful partnerships for health market innovations in Bangladesh and the extent to which these innovations can contribute to market systems changes that benefit the poor. The first case examines an innovation which aims to address maternal and child health issues by creating access to information on prenatal and post-natal care through mobile phones. The other case illustrates how Bangladesh's leading NGO partnered with one of the largest pharmaceutical companies in Bangladesh to develop a model for rural distribution of a micronutrient food supplement, 'sprinkles', to tackle the problem of micronutrient deficiency in young children.
\end{abstract}

\section{Introduction}

The achievements of Bangladesh in health service delivery are now globally acknowledged and have stirred global interest in the factors that might have contributed to the achievements. In their Lancet publication 'Community-based Approaches and Partnerships: Innovations in Health-service Delivery in Bangladesh', Arifeen et al. (2013) attributed the success to three factors: (1) application and adaptation of community-based approaches and community health workers at scale; (2) partnerships between the government and non-state actors; and (3) early and rapid adoption of innovations. The success of Bangladesh is further attributed to empowerment of women and the reach of the NGOs (The Guardian 2013). Das and Horton (2013) in their commentary 'Bangladesh: Innovating for Health' in the Lancet identified four factors: (1) the pluralism of the health-care sector in Bangladesh; (2) the continued focus on research; (3) increasing gender equity; and (4) strengthened international cooperation.

An interesting point here is that the role of the private sector is often discussed rather subtly in the context of the pluralism in health service delivery in Bangladesh. While discussing the agenda of 'Harnessing Pluralism for Better Health in Bangladesh', Ahmed et al. (2013) identified the formal and informal aspects of the private sector in health service delivery in Bangladesh. Formal providers include high-end secondary to tertiary level clinical service providers and training institutes while informal providers include the large cadre of village doctors, drug shop attendants, homeopathic practitioners and traditional medicine practitioners.

While these actors, who are directly involved in health service delivery, will continue to be the representatives of the private sector in health, findings from a UK Department for International Development (DFID) scoping study on innovations in health service delivery in Bangladesh reveal an emerging group of private sector actors who might dictate transformation towards new market systems in health services in Bangladesh.

Specifically, the scoping study highlighted that new health models are based on an evolving form of partnership between NGOs and the formal forprofit private sector. A closer review of the models further revealed what could be considered to be a new form of health market systems in which the formal for-profit private sector directly 
contributes to the conceptualisation, marketing and financing of health services. The private sector in these models includes not only private health facilities and pharmaceutical companies that play an active role in health provision, but also manufacturers of fast-moving consumer goods, telecommunication service providers, technology start-ups, social businesses and financial service providers.

But what makes these actors relevant in the context of Bangladesh's health systems? How are they going to shape health systems interventions in the future? What are their underlying interests in playing these roles? Does this signal a transformation to new market systems for health service delivery? Can such new systems deliver benefits for the poor? What role does the government play in harnessing the development? What are the implications of this development on the design and management of health systems projects in the future?

In this article the author reviews two cases from Bangladesh that provide insights into these evolving health market systems in which the collaboration between NGOs and formal forprofit private actors has played a key role in stimulating innovations in health service delivery. This is not a scientific paper but a practitioner's note that builds on the author's experience in designing, managing and evaluating development interventions that can deliver scalable and transformative impacts.

\section{Key concepts}

The case analyses presented here build on the following concepts.

Innovation: Innovation in this article refers to new, improved or previously untested approaches in health service delivery. This includes partnerships between state and non-state actors in which actors engage in new forms of collaboration based on mutual interest (commercial or social). Such innovations in service delivery are highly relevant for countries like Bangladesh where about 47 million people are estimated to be living below the poverty line (Bloom et al. 2013b) and where the limited access to health-care services has led to the evolution of pluralistic health market systems in which NGOs, informal providers and the private sector dominate health services (Bloom et al. 2013a).
Health market systems: The author adopts the concept of 'market systems' which is defined by the Springfield Centre (2014) as 'a multi-function and multi-player arrangement comprising the core function of exchange and the supporting functions and rules which are performed and shaped by a variety of market players'. The concept 'core function of exchange' needs some elaboration. Within a health system, different types of exchange can take place. This includes transactions in health services, health technologies, health information, health-care financing, medical education and so forth. Each of these transactions is conceived of as taking place in a specific market system - for instance, the health service delivery market system, health technologies market system and health financing market system.

It is critical to note here that the functions and roles of health systems actors change with respect to the markets within which they operate. For instance, the health service providers who are on the supply side in the health service delivery market are on the demand side in the market for health education and skill development. The financial service providers who undertake a supporting function in the health service delivery market are at the core of the exchange in the health financing market. The author believes that by deconstructing the broader health systems into specific health market systems the roles and functions of the market players and their interconnectedness could be better understood. The cases in this article are thus analysed in the context of specific health market systems rather than general health systems.

Financial viability/sustainability: In their report on health sector reforms in low- and middleincome countries, Knowles, Leighton and Stinson (1997) defined financial sustainability as the 'capacity of the health system to replace withdrawn donor funds with funds from other, usually domestic, sources' and sustainability of an individual programme as the 'capacity of the grantee to mobilize the resources to fund the recurrent costs of a project once it has terminated'. While this is specific to externally supported initiatives, given the nature of the health systems markets discussed in this article, the author uses these definitions here to assess the financial sustainability of the models that are reviewed. 
Transformative change: In relation to health projects, systemic change deals with the question 'what happens to the benefits provided by the project after the project support is withdrawn?' rather than only the direct and immediate benefit to the targeted population. Systemic or market systems change is defined by the Springfield Centre (2014) as 'a change in the way supporting functions and rules perform that ultimately improves the poor's terms of participation within the market system'. The following example of the difference in high-level outcomes between initiatives aimed at delivering vital health services to the poor and initiatives facilitating systemic change for the delivery was highlighted by Engineers Without Borders Canada (2014):

- Delivering vital health services: 'Decreasing infant mortality \& improving maternal health in a specific location over 5 years by training local staff and holding perinatal and antenatal clinics with mother care groups.'

\section{Systemic change in local health: 'At the end of} 5 years, public and private local clinics [across a wide geographic area are] providing affordable, high-quality maternal health services to new and expecting mothers for the foreseeable future, reducing infant mortality over time.'

In this example, it is clear that in both scenarios, the improvements will likely continue after support is withdrawn. However, the improvements in the first case will not necessarily spread beyond the locality of intervention, and improvements in services within this locality may or may not continue once the trained staff retire or leave. This leads to the next area of focus, related to scale.

Within development interventions, the term 'scaling up' is generally used to refer to the efforts undertaken by the project to achieve 'scale' (which often refers to the number of people reached by an intervention). In the World Bank (2003) working paper Scaling-up the Impact of Good Practices in Rural Development, scaling up is defined as '[an approach] to efficiently increase the socioeconomic impact from a small to a large scale of coverage.' However, this definition does not clarify whether the scale is being achieved by the project itself or by the actors in the systems supported by the project. If the project is the main driver behind scaling up then there is a risk that the scale is limited to the project's funding and effort. On the other hand, if the project facilitates the conditions for other market players to scale up then there is a chance that the project can break through beyond its own funding and efforts, thereby leading to a transformative change.

To assess the promise of a development intervention to deliver transformative change, the author adopts the concept of 'scalability'. In this article, the author defines scalability as the promise or the potential of a development intervention to reach more people in a wider geographic territory than originally targeted by the project and includes impact that the intervention can potentially achieve after the project support is withdrawn.

\section{Review of cases from Bangladesh}

In this section, the author reviews two cases that explore new forms of collaboration between the non-profit and for-profit sectors and the potential of these partnerships to deliver systemic health market changes, considering scalability, financial viability and pro-poor benefits. The first case examines an innovation which aims to address maternal and child health issues by creating access to information on prenatal and post-natal care through mobile phones. The other case illustrates how one of the largest NGOs in Bangladesh partnered with one of the largest pharmaceutical companies in Bangladesh to develop a viable model for rural distribution of a micronutrient food supplement, 'sprinkles,' to tackle the problem of micronutrient deficiency among children aged 6-23 months.

\section{Case 1: Mobile phone technology and NGO front-line health services merge to provide prenatal and post-natal care information: the case of Aponjon}

\section{Background: Walton and Schbley (2013)}

reported a positive link between skilled prenatal and post-partum education and improved outcomes and decreased maternal morbidity and mortality. Typically, the delivery of prenatal and post-partum education relies on a health-care system that can reach out to pregnant women and mothers of newborns. But there is a significant gap in access to such health care in 
Bangladesh. According to Koenig et al. (2007), 48 per cent of the respondents of a national study conducted on 103,000 Bangladeshi female subjects reported not receiving any type of prenatal or post-partum health care. While not addressing the lack of care, Aponjon, managed by a social enterprise, Dnet, aims to address the lack of prepartum and post-natal information through a subscription-based service that provides information to mothers and their gatekeepers (for example husbands, mothers and mothers-in-law of expectant or new mothers).

The service is designed to provide information on prenatal and post-natal practices through instant voice-recorded messages or Short Message Service (SMS) (based on the preference of the subscriber (Alam and Raihan 2014)). The service was introduced in Bangladesh in September 2011, under the global public-private initiative called Mobile Alliance for Maternal Action (MAMA), and launched by the United States Agency for International Development (USAID) and Johnson \& Johnson, in collaboration with the United Nations Foundation, the mHealth Alliance, and BabyCenter LLC (Rajan et al. 2013).

\section{Significance of partnership in Aponjon:}

Aponjon has a complex partnership arrangement that includes NGOs, private sector and public sector stakeholders. The partners in Aponjon provide outreach, content development, content regulation and financial support. Based on available literature, the objectives and roles of the different partners and their incentives in Aponjon can be defined as below:

- Outreach: The NGOs and non-profit partners provide outreach support for enrolment of subscribers. Partners include BRAC, the USAID NGO Health Service Delivery Project, the USAID MaMoni Project, Fair Price International Private Limited Company (Dnet Infolady Social Entrepreneurship Programme), the Social Marketing Company (SMC) and Union Information and Service Centres (UISCs) operated by the Access to Information (A2I) programme under the Prime Minister's Office, Government of Bangladesh. The health workers of the outreach partners, who are called community agents, are trained by the Aponjon programme and are provided cash incentives for acquiring subscribers, data entry and promotion through fairs and backyard meetings (Dnet 2014). The ability to leverage this large pool of community health workers in Bangladesh could arguably be one of the factors contributing to the transformation of health systems in Bangladesh.

- Content development: A subsidiary of Dnet, Multimedia Content and Communication Limited (MCCL), manages the task of content development. The content is based on ethnographic research on a mother's awareness of government-circulated messages related to pregnancy and childcare. Further to that, the process involves review by an expert panel consisting of Bangladeshi physicians, researchers and communications professionals. BabyCenter, an internationally recognised web-based information service provider on maternal and newborn care (see www.babycenter.com), provides advisory support for content development (Rajan et al. 2013).

\section{- Content regulation and engagement of} government agencies: The roles of public agencies in the partnership are twofold: (1) regulation of content and the services provided and (2) leveraging a public-private partnership to achieve the government's goal related to promoting digital innovation and development in agriculture, health, education and governance systems in general. The Bangladesh Ministry of Health and Family Welfare (MoHFW) and the A2I programme are the official government partners of Aponjon. The MoHFW reviews and approves the contents provided by Aponjon. The A2I programme, as mentioned earlier, is one of the outreach partners. Other public agencies involved in outreach include the government's Community Clinic Project, ${ }^{1}$ the Directorate General of Health Services (DGHS) and Directorate General of Family Planning (DGFP). Apart from these, the Bangladesh Telecommunication Regulatory Commission (BTRG) provides coordination support for Aponjon to reach out to mobile phone operators in Bangladesh.

- Financing: Aponjon has a strong focus on corporate sponsorship for financing. USAID and Johnson \& Johnson provide seed financing for 20 per cent of the costs of the Aponjon initiative under the Maternal and Child Health Integrated Programme (MCHIP) until 
June 2015. Additional corporate sponsors include Beximco Pharma, one of the largest pharmaceutical companies in Bangladesh, Lal Teer Seeds Limited, one of the largest agribusiness companies in Bangladesh and Agora, the largest supermarket chain in Bangladesh.

Apart from financing, the corporate partners are also engaged in promoting Aponjon services. Beximco is promoting Aponjon through its countrywide network of doctors. Lal Teer Seeds promotes Aponjon in its leaflets, calendars, posters, banners and signboards. Agora is supporting a campaign called 'Sponsor a Mother' under which a customer of Agora can buy a token gift and sponsor a mother for a total of 86 weeks. Dnet uses the funds generated through this campaign to provide free services to poor households who cannot access the service for free.

\section{Knowledge management and international} outreach: The United Nations Foundation provides support for communications, advocacy and public outreach, and provides linkages between the implementing agencies of MAMA in Bangladesh, India and South Africa. The mHealth Alliance serves as MAMA Secretariat, and provides technical mhealth expertise and a forum to exchange knowledge and share best practices (Lemaire 2013).

Incentives of the partners: According to Dnet, the partnership between the NGOs and Aponjon is mutually beneficial: the NGOs benefit from engagement of their community health workers in income-generating activities through the enrolment of the subscribers and through the sale of products supplied by other partners, including SMC, the largest supplier of contraceptives, micronutrient powder (MNP) and safe delivery kits in Bangladesh. As of June 2014, as many as 1,373 community health workers from BRAC were engaged in enrolling subscribers for Aponjon in 101 upazillas of 16 districts in Bangladesh (see www.aponjon.com.bd). This helps Aponjon save costs in developing and maintaining a large pool of outreach service providers across Bangladesh.

Aponjon also provides Dnet an opportunity to generate revenue for its other concerns - for instance, MCGL which is engaged in content development.
By partnering with Aponjon, the Government of Bangladesh is able to test the effectiveness of public-private partnerships to achieve its goal of creating a 'digital Bangladesh and in [the] context of health systems, test the effectiveness of digital innovation on health outcomes'.

\section{Corporate sponsors like Beximco benefit from} tax exemption due to their investment in Aponjon under the corporate social responsibility (CSR) agenda. Lal Teer Seeds has both CSR and commercial benefit. By providing messages on Aponjon on seed packets, Lal Teer is able to position itself as a company having social interest, which can potentially translate into customer retention.

Most of the customers in Agora, the supermarket chain that has partnered with Aponjon, are urban women, the target group that generates a large part of the revenue for Aponjon (further detailed later in this case). Agora too is expected to benefit from leveraging on the social or the CSR agenda. However, the impact of CSR on corporate sales is a subject that is yet to be researched.

\section{Pathway towards transformative change - prospects and challenges:}

Scalability: The case suggests that though the service is being tested under a programme and the primary (seed) funding is international aid, the service is designed, tested, promoted and scaled up by actors embedded in the market systems. As per the definition of scalability adopted for this article, an innovation is scalable if the market players rather than the project drive the effort towards achieving scale. The project is run by Dnet, a social business and therefore a market player which has the commercial and social interest to continue the service beyond the project's tenure. Dnet is supported by a band of outreach partners that belong to the market systems of health information, including NGOs and government agencies. The partnership with local corporate sponsors, who have become new actors in the health information market systems, provides the potential to evolve as increasing the subscription base of Aponjon could potentially attract more corporate sponsors who have a similar strategic fit to sponsor Aponjon under their CSR budget. Thus, Aponjon aims to engage more corporate sponsors for rapid 
scale-up. The roles of government agencies and international partners are also based on mutual interest and are expected to continue beyond the time frame (three years) for which the seed financing is made available. The model thus does have the potential to be scalable. But this depends on the degree to which it is financially viable once the seed financing is withdrawn. This is further analysed below.

- Financial viability: The Aponjon service is currently highly subsidised. The subscription fee for each message (approximately 2.5 US cents) is much lower than the development cost per message (approximately 40 US cents; Bloom et al. 2013b). However, the service is expected to become self-sustaining once it reaches the subscription base of 2 million (ibid.). This means once it reaches the 2 million subscriptions base, it will no longer require financing through international aid or through corporate financing. With around 60,000 subscribers added per month (data as of March 2014, as per GSMA 2014), and a current base of 1.2 million subscribers, it is expected to reach its stated target of 2 million and therefore its financial viability by the end of 2015 (see www.mobilemamaalliance.org/mamabangladesh).

In addition, Aponjon is reportedly considering development of an application through which higher revenue generated from upper income segments could be used to cross-subsidise the basic service to the poorest mothers in Bangladesh (see above website). It is also adopting new and innovative mechanisms to cut operating costs. Dnet has now introduced mobile money for the financial management of the community health workers under the outreach partners and this has nearly halved the cost of fund disbursement (Dnet 2014). The model thus appears to be evolving with the market by adopting new technologies and service delivery models. From this account it can be suggested that market-driven solutions which continue to evolve as they mature further increases the likelihood of becoming financially viable.

- Reaching the poorest: The service of Aponjon is not exclusively targeted for the poor.

According to Dnet, 41 per cent of its subscribers are poor (average monthly household income of BDT5,000-10,000). Around 5 per cent of the subscribers belong to the poorest of the poor category, having an average household income of less than BDT5,000 per month. Subscribers belonging to the lower middleincome category (average monthly household income of BDT10,001-20,000) are significant: 37 per cent of the total. The remaining 17 per cent belong to the middle- and higher middleincome categories. Moving forward, can Aponjon increase its outreach to the poor? The idea to tax subscribers belonging to the upper category to cross-subsidise free services to the poor suggests that there is a strategy in place to maximise pro-poor outreach. But this also suggests that market-driven solutions might not be exclusively pro-poor. A risk here could be that once the seed financing is exhausted, the drive to sustain financial viability might lead to rapid outreach to the non-poor rather than the poor, thereby offsetting the benefit to the poor. This is nevertheless a hypothesis that needs to be reviewed in the long run.

\section{- Health outcomes: A survey undertaken to} assess the impact of the Aponjon service on public health suggests positive outcomes. This includes an increase in antenatal care (ANG) visits (37 per cent of users compared to a 2011 national baseline of 26 per cent attending four ANC visits), a relatively high rate of exclusive breastfeeding (83 per cent of the new mothers registered with Aponjon) and a high immunisation rate of BCG (tuberculosis) (96 per cent) and Pentavalet (100 per cent) (Ahsan and Raihan 2013).

However, data on the contribution of Aponjon towards national health outcomes is not yet available. This is primarily because of the fact that the service is relatively new in the health system and has yet to become a driver at a scale that can dictate national health outcomes. But even in the long run, will it have a positive impact on national health outcomes related to maternal, newborn and child health (MNCH)? If yes, at what scale can it deliver such impact? Will it be possible for Aponjon to achieve such scale on its own or is there a requirement for renewed funding and support from agencies that include the government and possible expansion through engagement of new providers? It would be 
worthy to evaluate the impact of Aponjon in the overall health systems in the long run to ascertain its contribution in transforming the health information market systems specifically related to information for prenatal and post-natal care.

\section{Case 2: NGO-pharmaceutical company collaboration for two-tier distribution ensures rapid scale-up, pro-poor outreach and financial viability for MNP: the case of Pushtikona}

Background: Micronutrient malnutrition caused largely by iron, iodine, vitamin A and zinc deficiencies are common among young children and lead to poor growth, impaired cognitive development, susceptibility to infections and diminishing economic outcomes during adulthood (Afsana et al. 2014). As per findings from the Bangladesh Demographic and Health Survey 2011, 51 per cent of children aged 6-23 months are suffering from anaemia (NIPORT et al. 2013). The National Micronutrient Survey (2011-12) recorded a zinc deficiency at a prevalence of 44.6 per cent among preschool aged children. Based on a study from 2006, the National Micronutrient Survey (2011-12) estimates that about 19.6 per cent of young children are suffering from vitamin A deficiency.

Pushtikona is a brand name of a micronutrient 'sprinkles' powder that contains 15 essential minerals and vitamins that are intended to improve the nutritional value of complementary foods (see www.pushtikona.com). The product is being marketed under the Bangladesh Sprinkles Programme (BSP), which started in 2009 as a collaborative effort between Renata Limited, a leading pharmaceutical company in Bangladesh, BRAC, the leading NGO in Bangladesh, and the Global Alliance for Improved Nutrition (GAIN). Originally developed by the Sprinkles Global Health Initiative (SGHI), one of the technical partners of the project, the product 'Pushtikona' was introduced for the prevention of anaemia due to iron deficiency, growth retardation due to zinc deficiency and gastrointestinal infections related to deficiencies in vitamin $\mathrm{A}$ and other nutrients (see www.pushtikona.com).

\section{Significance of partnerships in Pushtikona:}

The partners include Renata Limited, one of the leading pharmaceutical companies in Bangladesh, BRAC and GAIN. In the new phase of the programme, ICDDR,B (International Centre for Diarrhoeal Disease Research, Bangladesh) and the Government of Bangladesh are being engaged (see www.gainhealth.org). This review is, however, limited to the partners and the partnership of the last phase, given that the scope of the new partners could not be validated through secondary research.

Manufacturing: Renata Limited invested in the production facility and manufactures the product in line with World Health Organization (WHO) recommendations (GAIN 2012). The investment from Renata on manufacture and marketing of the product can be associated with the fact that the majority of the share of Renata is owned by Sajida Foundation, one of the leading NGOs in Bangladesh which focuses on public health and poverty alleviation (ibid.).

Distribution; pro-poor outreach: The model involves a two-tier distribution channel: (1) a commercial channel that builds on Renata's national network covering 90 per cent of the pharmacies in Bangladesh (GAIN 2012); and (2) an institutional channel that builds on BRAC's cadre of 97,000 community health workers called Shasthya Sebikas (Afsana et al. 2014) and reaches out the bottom of the pyramid to the poorest of the poor population. In the commercial channel, Renata distributes the product for BTK2.50 (3 US cents) per sachet through a network of about 1,100 medical representatives reaching out to around 50,000 doctors across Bangladesh (Bloom et al. 2013b). In the institutional channel BRAC purchases the product for BTK1.55 (1.9 US cents) per sachet and distributes it through its band of community health workers who sell the product for a minimum profit (margin unknown) (GAIN 2012).

Currently, BRAC is distributing the MNP in 61 districts (463 sub-districts) of Bangladesh through its community health workers (Afsana $e t$ al. 2014). BRAC implements the intervention in a more intensive way with complementary feeding practices in 50 districts under the Alive and Thrive initiative supported by the Bill and Melinda Gates Foundation (BMGF) with leadership from Family Health International 360. BRAC also distributes part of the product to ultrapoor households under BRAC's Ultra-Poor Programme (Bloom et al. 2013b). In 2012, BRAC distributed 16 per cent of its total volume of MNP 
to the children of ultra-poor households free of cost (Afsana et al. 2014).

Marketing: Because of the distinct capacities of Renata and BRAC, the partnership offers demand creation approaches that could be tailored to the need of the urban and the rural market (GAIN 2012). While Renata focuses on its experience in advertising campaigns, BRAC builds on its experience in behavioural change communications and also transfers knowledge about the use of the product through its cadre of community health workers (Afsana et al. 2014).

Quality control: It is not clear from available literature what role the government has in controlling the quality of the MNP, although it does suggest that the product is manufactured as per WHO guidelines (GAIN 2012). However, for the MNP to effectively reduce deficiencies, a child must be given a minimum of 60 single-dose sachets with no more than one sachet a day over 60 days. Following this, 60 sachets should be consumed every six months until a child's haemoglobin levels rise above the cut-off for anaemia. In the institutional channel, BRAC's health workers monitor compliance, and the programme has acknowledged that ensuring children consume the minimum dosage is a challenge that is still to be addressed (Afsana $e t$ al. 2014). However, there is no formal account of monitoring in the commercial channel.

Financing: GAIN invested US $\$ 3$ million with funding from the BMGF in the first phase of the programme (2009-13). The financing from GAIN in the first phase was used on a costsharing basis to provide technical assistance and to support Renata in establishing the production facilities and marketing the product. GAIN also provided funding to BRAC to train community health workers (Bloom et al. 2013b). The programme has now entered a new phase (2013-18) with a US $\$ 27.5$ million grant from the Children's Investment Fund Foundation (CIFF) (see www.cooperationinternationalegeneve.ch). The financial viability of the model is further analysed in the subsequent section of this case.

Incentives of the partners: The two-tier distribution system is mutually beneficial for Renata and BRAC. Renata gains from an assured institutional market reached through BRAC, the institutional buyer. On the other hand, BRAC has two main incentives: (1) it can leverage the partnership to achieve deeper health impacts through its complementary feeding initiatives; and (2) the partnership provides BRAC with an opportunity to create income-generating opportunities for its large cadre of community health workers.

Health impact: The Alive and Thrive initiative focused on breastfeeding and complementary feeding and a preliminary evaluation (IFPRI 2013) suggests a number of improvements in infant and young child feeding (IYCF) practices as a result of the overall initiative. However, the report does not provide data specifically related to the MNP to indicate the effectiveness of the initiative in reducing micronutrient deficiencies. Thus, there is a need to assess the impact achieved by distribution of sprinkles in programme areas apart from Alive and Thrive. This would provide a critical understanding of the impact on micronutrient deficiency that could be achieved through the use of micronutrient sprinkles.

\section{Pathway towards transformative change - prospects and challenges}

Scalability: In terms of scale, production has steadily increased over the period 2009-13 and in 2013, Renata produced nearly 34 million sachets of MNP, of which about 14.5 million sachets were distributed through the delivery networks of BRAC's community health workers (Afsana et al. 2014). The simultaneous focus on urban and rural markets and the distinctive capacities of BRAC and Renata means that the partners are not cannibalising each other's market and can expand the market base. The programme was expected to benefit 6.8 million children under the age of two, though available literature does not provide an account of the number of children reached.

However, in terms of scalability, a key point to note is that in this model, GAIN works as central to the coordination between BRAC and Renata for the distribution of the commodities through different channels. Thus, unlike the Aponjon model where a market player is tasked to manage the system, in the Pushtikona model a pseudo or a temporary market player like GAIN is leading 
the management system. This is against the principle of scalability since the relationship between the market players and therefore the continuity of the model could be threatened once GAIN withdraws itself from the system.

Financial viability: While it is evident that the partnership between BRAC and Renata is mutually beneficial, whether the partnership can continue without financial assistance is a question to be answered. However, the model is not entirely dependent on aid finance, since Renata co-invested on the programme and markets the product through its own channel in addition to that of BRAC. The literature suggests that the donor financing is primarily used for rural outreach which involves investment for training of community health workers as the model is scaled up to reach more people. From these accounts we can assume that the urban component managed by Renata is not dependent on aid. However, the rural component of the programme depends on subsidy and free distribution to the poor. The renewed funding of US $\$ 27$ million is a testimony to the fact that the model is yet to become a significant market force on its own to be able to achieve its full potential without further development assistance. Review of the degree to which the programme is benefiting the poor provides further insight into the challenges that call for continued development assistance. Also, from the review of the literature the author was not able to determine whether there is a plan to cross-subsidise the rural distribution through revenue generated by Renata from the commercial distribution. It can nevertheless be stated that the prospect for cross-subsidisation is low since the two systems are operated by two different entities.

- Reach to the poorest: Review of the existing literature on the model reveals two challenges with respect to scalable pro-poor outreach. Firstly, according to BRAC there is still a need to review the incentives of the front-line health workers and the pricing structure to keep the product within the reach of the targeted population (Afsana et al. 2014). This suggests that the income from the sales of the product is not at the level to incentivise the community health workers to push the product to the market at scale. Secondly, ultra-poor outreach is dependent on free distribution by BRAC and is therefore yet to become market-led. BRAC is yet to test a model whereby revenue generated by distribution to the wealthier class in the rural markets could be used to fund the distribution to the ultra-poor.

Further, rural distribution is dependent on BRAC's community health workers and a subsidy on the wholesale price. It is not clear how the subsidy is financed and whether the subsidy is borne by BRAC through external funding. A review undertaken by BRAC suggests the need for further efforts to increase the knowledge of mothers and care givers, increase compliance to dosage requirements and change cultural norms related to home-based feeding practices for children. It thus appears that the model might face difficulties with respect to pro-poor outreach if it is left to the market at this stage.

\section{Discussion and conclusions}

The review of these two cases reveals a number of interesting insights related to health market system interventions with respect to partnerships, financial viability and pro-poor benefits.

Related to partnerships, in both of the cases reviewed, partners were involved from the public and private sectors across different market systems. The cases reviewed suggest that synergy of incentives of the partners is a key determinant of partnerships. In both models, partners have mutually reinforcing incentives which make the partnerships work. The cases also suggest that the partnerships are being built on developments in different market systems: the NGO health service delivery system, the pharmaceuticals market systems and the telecommunications market system. This suggests a need to understand the potential interconnectedness of market systems beyond those specifically related to health to determine the factors that could drive transformative change.

It is also noteworthy to mention that achieving transformative market changes (i.e. crowding in) may be against the interest of a company involved in the innovation. If achieving market systems changes is a key aim, then it might necessitate the involvement of a third party. The Pushtikona model in this respect has better potential for 
transformative change than the Aponjon model where Dnet has disincentive (being a commercial provider by itself) to allow more market players to adopt the same innovation for service delivery. However, the dependence on GAIN in the Pushtikona case potentially undermines the sustainability of the model. Surprisingly, both initiatives are silent about the role of the Bangladeshi government in sustaining efforts or stimulating systemic change.

Financial viability was a significant issue for these case studies. The cases reviewed suggest three forms of financing that development aid could leverage for financial viability of health programmes: (1) corporate sponsorship in which a for-profit company provides cash or in kind support under the banner of CSR; (2) crosssubsidy in which revenue generated from a profit-making channel could be used to subsidise a non-profit-making channel targeting the poor; and (3) funding provided through a development initiative to get the market solution to a point at which it is self-sustaining. This third avenue may or may not be delivered via match funding, in which a for-profit company co-invests to develop the scheme. More work would be needed to compare the situations under which these forms of financing can result in viable pro-poor market systems changes in the health-care sector in Bangladesh.

The cases also suggest that market solutions might not be exclusively pro-poor. In both cases, the business models reach out to both poor and non-poor beneficiaries, and these dual markets appear to be key to the viability of the initiatives, even where cross-subsidy is not taking place (for example, in the case of micronutrient sprinkles). This might be an indication that market-driven solutions might fail to deliver if designed exclusively for the poor. However, this also raises the risk that once the donor funding is pulled out, market-driven solutions could be driven away from the poor if the financial viability and scalability of pro-poor outreach is not sustained within the time frame for which the donor support is available.

In terms of the actual impacts experienced by the poor, none of the cases reviewed provide a clear analysis of contribution of the models to national or regional health outcomes. The monitoring and evaluation system of programmes assess the reach of the programmes (in the case of Aponjon, the number of expectant mothers and mothers of newborns receiving the message and in the case of Pushtikona, the number of children receiving the MNP), but are lacking in measurement of the real changes in people's health or wellbeing and also in the extent to which systemic changes are occurring.

Finally, it is worth noting that the cases reviewed here were similar in a number of ways. Both are based on the sale of a product or service to the poor. They are also similar in that they leveraged the large pool of community health workers in Bangladesh, and involve the support of a nonprofit organisation. However, not all market systems initiatives will take this approach or have these resources to leverage. Thus, in addition to deepening the research on these two cases as more information becomes available, expanding this analysis to other health market interventions could yield interesting insights about the potential for such initiatives to achieve viability and scalability while also continuing to reach and impact on the poor.

\section{Note}

1 The title of the project is 'Revitalization of Community Health Care Initiatives in

Bangladesh'. 


\section{References}

(All websites accessed 6 March 2015)

Afsana, K.; Haque, R.M.; Sobhan, S. and Shahin, S.A. (2014) 'BRAC's Experience in Scaling Up MNP in Bangladesh', Asia Pacific Journal of Clinical Nutrition 23.3: 377-84

Ahmed, S.M.; Evans, T.G.; Standing, H. and Mahmud, S. (2013) 'Harnessing Pluralism for Better Health in Bangladesh', in 'Bangladesh: Innovation for Universal Health Coverage 3', Lancet 382: 1746-55

Ahsan, A. and Raihan, A. (2013) 'Understanding mHealth Impact among Aponjon (MAMA Bangladesh) Subscribers through a Phone Survey in Bangladesh', in ICTD 13 Proceedings of the Sixth International Conference on Information and Communications Technologies and Development: Notes 2, New York NY: ACM

Alam, M. and Raihan, A. (2014) Assessing the Impact of Mobile Health Messages among Expectant Women and New Mothers - Case Study Aponjon, Aponjon: USAID

Arifeen, S.E.; Christou, A.; Reichenbach, L.; Osman, F.A.; Azad, K.; Islam, K.S.; Ahmed, F.; Perry, H.B. and Peter, D.H. (2013) 'Communitybased Approaches and Partnerships: Innovations in Health-service Delivery in Bangladesh', in 'Bangladesh: Innovation for Universal Health Coverage 3', Lancet 382: 2012-26

Bloom, G.; Kanjilal, B.; Lucas, H. and Standing, D.H. (2013a) Transforming Health Markets in Asia and Africa: Improving Quality and Access for the Poor, London: Routledge

Bloom, G.; Sarwar, R.: Standing, H.; Begum, T.; Rahman, S. and Wilkinson, A. (2013b) Innovations for Health in Bangladesh, Dhaka: SRIJON

Das, P. and Horton, R. (2013) 'Bangladesh: Innovating for Health', in 'Bangladesh: Innovation for Universal Health Coverage 3', Lancet 382.9906: 1681-82

Dnet (2014) Mobile Money Case Study: A Comparison between Cash and Mobile Payments in Dnet's Aponjon Program (MAMA Bangladesh), www.microlinks.org/library/mobile-money-casestudy-comparison-between-cash-and-mobilepayments-dnet $\%$ E2\%80\%99s-aponjon-program

Engineers Without Borders Canada (2014) Shifting Aid Models to Manage for Systemic Change, Engineers Without Borders Canada Briefing Paper, http://pollengroup.org/?p=18

GAIN (2012) A Child's Daily Nutrition Within a Small Sachet, case study on BRAC-Renata
Partnership, www.gainhealth.org/wp-content/ uploads/2014/04/63.-Case-Story.-A-childsdaily-nutrition-within-a-small-sachet.Micronutrient-Powders-in-Bangladesh..pdf GSMA (2014) Snapshot: MAMA in Bangladesh: Including Men in Mobile Services for Women, GSMA mWomen, www.gsma.com/mobilefor development/wp-content/uploads/2014/04/ Snapshot-MAMA-in-Bangladesh.pdf IFPRI (2013) Alive \&̊ Thrive Process Evaluation Report 2013: Preliminary Report, Dhaka: International Food Policy and Research Institute

Knowles, J.C.; Leighton, C. and Stinson, W. (1997) Measuring Results of Health Sector Reform for System Performance: A Handbook of Indicators, Special Initiatives Report 1, Bethesda MD: Abt Associates, Partnerships for Health Reform Project

Koenig, Michael A.; Jamil, K.; Streatfield, P. et al. (2007) 'Maternal Health and Care-Seeking Behavior in Bangladesh: Findings from a National Survey', International Family Planning Perspectives 33.2

Lemaire, J. (2013) Scaling up Mobile Health: Developing mHealth Partnerships for Scale, Geneva: Advanced Development for Africa NIPORT (National Institute of Population

Research and Training), Mitra and Associates, and ICF International (2013) Bangladesh Demographic and Health Survey 2011, Dhaka, Bangladesh and Calverton MD: NIPORT, Mitra and Associates, and ICF International Rajan R.; Raihan, A.; Alam, M.; Agarwal, S.; Ahsan, A.; Bashir, R.; Lefevre, A.; Kennedy, C. and Labrique, A.B. (2013) MAMA 'APONJON' Formative Research Report, Baltimore MD: Johns Hopkins University Global mHealth Initiative Springfield Gentre (2014) The Operational Guide for Making Markets Work for the Poor (M4P) Approach, Durham: Springfield Centre

The Guardian (2013) 'Healthcare in Bangladesh Soars Despite Widespread Poverty, Study Shows', 21 November, www.theguardian.com/ global-development/2013/nov/21/bangladeshhealthcare-poverty-lancet-study

Walton, L.M. and Schbley, B. (2013) 'Maternal Healthcare in Bangladesh and Gender Equity: A Review Article', Online Journal of Health Ethics 9.1, http://aquila.usm.edu/cgi/ viewcontent.cgi?article $=1047 \&$ context $=$ ojhe WHO (2011) mHealth: New Horizons for Health through Mobile Technologies - Based on the Findings of the Second Global Survey on eHealth, World 
Health Organization Global Observatory for eHealth Series Volume 3, www.who.int/goe/ publications/goe_mhealth_web.pdf

WHO (2010) Health System in Bangladesh, http://www.ban.searo.who.int/en/Section25.htm World Bank (2003) Scaling-up the Impact of Good

Practices in Rural Development: A Working Paper to
Support Implementation of the World Bank's Rural Development Strategy, World Bank Agriculture and Rural Development Department Report 26031, Washington DC: World Bank 